\title{
CHIP Suppresses Polyglutamine Aggregation and Toxicity In Vitro and In Vivo
}

\author{
Victor M. Miller, ${ }^{1,2}$ Rick F. Nelson, ${ }^{1,3,4}$ Cynthia M. Gouvion, ${ }^{1}$ Aislinn Williams, ${ }^{1,3,4}$ Edgardo Rodriguez-Lebron, ${ }^{1}$ \\ Scott Q. Harper, ${ }^{5}$ Beverly L. Davidson, ${ }^{1,2,3,5}$ Michael R. Rebagliati, ${ }^{2,6}$ and Henry L. Paulson ${ }^{1,2,3,4}$ \\ ${ }^{1}$ Department of Neurology, ${ }^{2}$ Graduate Program in Genetics, ${ }^{3}$ Graduate Program in Neuroscience, ${ }^{4}$ Medical Scientist Training Program, ${ }^{5}$ Department of \\ Internal Medicine and Department of Physiology and Biophysics, and ${ }^{6}$ Department of Anatomy and Cell Biology, University of Iowa Roy J. and Lucille A. \\ Carver College of Medicine, Iowa City, Iowa 52242
}

Huntington's disease (HD) and other polyglutamine (polyQ) neurodegenerative diseases are characterized by neuronal accumulation of the disease protein, suggesting that the cellular ability to handle abnormal proteins is compromised. As both a cochaperone and ubiquitin ligase, the C-terminal Hsp70 (heat shock protein 70)-interacting protein (CHIP) links the two major arms of protein quality control, molecular chaperones, and the ubiquitin-proteasome system. Here, we demonstrate that CHIP suppresses polyQ aggregation and toxicity in transfected cell lines, primary neurons, and a novel zebrafish model of disease. Suppression by CHIP requires its cochaperone function, suggesting that CHIP acts to facilitate the solubility of mutant polyQ proteins through its interactions with chaperones. Conversely, HD transgenic mice that are haploinsufficient for CHIP display a markedly accelerated disease phenotype. We conclude that CHIP is a critical mediator of the neuronal response to misfolded polyQ protein and represents a potential therapeutic target in this important class of neurodegenerative diseases.

Key words: polyQ; CHIP; zebrafish; neurodegeneration; proteasome; molecular chaperones

\section{Introduction}

Molecular chaperones participate in nascent protein folding and the refolding of proteins damaged by physiological stress or mutations. If a native conformation cannot be achieved, futile refolding efforts by chaperones either continue or the protein is targeted for degradation. For many damaged or misfolded proteins, the principal route for this degradation is the ubiquitinproteasome pathway (UPP) (Hartl and Hayer-Hartl, 2002; Berke and Paulson, 2003). To triage proteins correctly between refolding and degradation, cells must possess molecular links between these two pathways (Cyr et al., 2002).

C-terminal heat shock protein 70 (Hsp70)-interacting protein (CHIP) is one such link. CHIP has three tetratrico peptide repeat (TPR) domains that interact with the molecular chaperones Hsp70 and Hsp90 and an E4/U-box domain that interacts with the proteasome and confers E3 ubiquitin ligase activity on CHIP (Ballinger et al., 1999; Jiang et al., 2001). CHIP enhances refolding of some proteins while facilitating the ubiquitination and clearance of others (Connell et al., 2001; Meacham et al., 2001; Kampinga et al., 2003). It can also regulate heat shock transcrip-

Received July 8, 2004; revised Aug. 16, 2005; accepted Aug. 17, 2005.

This work was supported by National Institutes of Health Predoctoral Training Grants T32 GM08629 (to the University of lowa Program in Genetics and V.M.M.), F30 NS047872 (R.F.N.), and NS38712 and NS47535 (H.L.P.), and by grants from the Ataxia Machado-Joseph disease Research Project and the National Ataxia Foundation (H.L.P.). We thank Cam Patterson for generously providing CHIP constructs and knock-out mice. We also thank members of the Paulson laboratory for critical, helpful comments on this research and manuscript.

Correspondence should be addressed to Dr. Henry L. Paulson, Department of Neurology, University of lowa College of Medicine, 2007 Roy Carver Pavillion, lowa City, IA 52242. E-mail: henry-paulson@uiowa.edu.

DOI:10.1523/JNEUROSCI.3001-05.2005

Copyright $\odot 2005$ Society for Neuroscience $\quad$ 0270-6474/05/259152-10\$15.00/0 tion factor 1 (HSF1), the principal transcription factor modulating chaperone expression during stress (Dai et al., 2003). Thus, CHIP is strategically positioned within the protein quality control (QC) systems of the cell.

The process of QC is crucial for neurons, which must function for decades in the face of high metabolic demands, environmental insults, and age-related physiological changes. Genetic mutations can further predispose neurons to pathological failures of QC, manifesting as neurodegenerative disease. An important example is the group of dominantly inherited diseases caused by polyglutamine (polyQ) expansion that includes Huntington's disease (HD) and at least eight other neurodegenerative diseases (Taylor et al., 2002).

polyQ neurodegeneration is accompanied by the formation of neuronal inclusions that sequester molecular chaperones and proteasome components. This fact suggests that perturbations in protein homeostasis contribute to polyQ pathogenesis (Cummings et al., 1998; Chai et al., 1999a,b; Satyal et al., 2000). Consistent with this view, studies in many polyQ model systems have shown that impairing QC systems can worsen disease and that boosting their activity can suppress neurodegeneration (Bence et al., 2001; Chan et al., 2002; Venkatraman et al., 2004). Moreover, genetic screens have confirmed the importance of both chaperone and degradation pathways in polyQ disease (FernandezFunez et al., 2000; Willingham et al., 2003; Nollen et al., 2004).

The positioning of CHIP as a potential integrator of QC activities suggested to us that it might participate in the cellular handling of mutant polyQ proteins. Here, using several complementary systems, we explore the ability of CHIP to modulate the cellular response to mutant polyQ proteins. In cell-based models, 
we show that CHIP reduces accumulation of insoluble aggregates in a manner that requires the TPR domain, implying that CHIP increases cellular capacity to maintain polyQ proteins in a soluble state. CHIP is also shown to reduce polyQ aggregation and toxicity in primary neurons in vitro. We then test the ability of CHIP to modulate toxicity in zebrafish, taking advantage of several powerful features of this novel vertebrate system. Finally, building on these results, we show that inactivation of a single copy of endogenous CHIP markedly accelerates disease in an HD transgenic mouse model.

\section{Materials and Methods}

Plasmid construction. The Q19-, Q35-, Q56-, and Q80-GFP and -GFPu and CHIP plasmids were described previously (Onodera et al., 1997; Bence et al., 2001; Connell et al., 2001; Meacham et al., 2001). To construct Q19-GFPu and Q80-GFPu, the polyQ fragment and part of the enhanced green fluorescent protein (GFP) coding sequence was cut from Q19- and Q80-GFP as a NheI to BsrgI fragment and ligated into the degron-modified GFP (GFPu) plasmid digested with NheI and BsrgI. Plasmids were verified by partial sequencing and immunoblotting with anti-GFP and 1C2 antibodies (Trottier et al., 1995). GFP-Q82-Htt is an in-frame $\mathrm{N}$-terminal fusion of GFP to truncated human huntingtin (Htt) comprising human exons $1-3$. The fusion protein was generated using recombinant PCR, and the final $1.4 \mathrm{~kb}$ product was cloned into pcDNA3.1.

Cell culture and transfections. All transfections were performed as described previously using Lipofectamine Plus (Invitrogen, Gaithersburg, MD) (Pittman et al., 1993; Chai et al., 1999a). For experiments assessing aggregate suppression, $1 \mu \mathrm{g}$ of plasmid encoding the polyQ proteins was cotransfected with $2 \mu \mathrm{g}$ of CHIP or pcDNA3 as an empty vector control. For experiments using geldanamycin (Sigma, St. Louis, MO), drug was dissolved in DMSO to a concentration of $360 \mu \mathrm{M}$ and applied as described previously (Sittler et al., 2001). Lactacystin (Calbiochem, La Jolla, CA) was added at a concentration of $10 \mu \mathrm{M} 18 \mathrm{~h}$ after transfection and continued for $30 \mathrm{~h}$.

Western blotting and immunofluorescence. Cos-7 cells were harvested $48-72 \mathrm{~h}$ after transfection and subjected to Western blot analysis as described previously (Chai et al., 1999a). The 1C2 antibody (1:1000 dilution) was used to detect the polyQ epitope in GFP-Q82-Htt. Q19- and Q71-GFPu were detected with anti-GFP (1:1000 dilution; Medical and Biological Laboratories, Naka-ku Nagoya, Japan). CHIP was detected using either an anti-CHIP polyclonal antibody to full-length recombinant CHIP (Oncogene Research Products, San Diego, CA) or an antiCHIP peptide antibody raised against amino acids 218-232 of human CHIP (Abcam, Cambridge, MA) both at a 1:1000 dilution. Hsp70 was detected using a polyclonal Hsp70 antibody (1:5000; Stressgen, Victoria, British Columbia, Canada). Anti- $\alpha$-tubulin mouse monoclonal antibody (1:10,000; Sigma) was used as a loading control.

Cos-7, PC-12, or primary neuronal cells were grown on coverslips, and immunofluorescence for CHIP was performed using an anti-CHIP peptide antibody raised against amino acids 218-232 of human CHIP (1:50; Abcam). Fluorescence was detected using rhodamine-conjugated secondary antibody (1:1000). Fluorescence was visualized with an Axioplan fluorescence microscope (magnification, $630 \times$ and $1000 \times$; Zeiss, Thornwood, NY). Images were captured digitally with a Zeiss MRM AxioCam camera and assembled in Photoshop 6.0 (Adobe Systems, Mountain View, CA).

Pulse/chase experiments. Transfected Cos-7 cells were labeled with 225 $\mu \mathrm{Ci}$ of ${ }^{35} \mathrm{~S}$-methionine for $30 \mathrm{~min}$, washed three times, and chased with media containing $45 \mathrm{mg} / \mathrm{L}$ unlabeled methionine for the indicated times. Cells were lysed under nondenaturing conditions in radioimmunoprecipitation assay (RIPA) buffer with protease inhibitors (PIs). GFP-Q82Htt was immunoprecipitated with $2.5 \mu \mathrm{g}$ of anti-GFP antibody (clones 7.1 and 13.1; Roche, Basel, Switzerland) for $1 \mathrm{~h}$ at $4^{\circ} \mathrm{C}$ and washed four times with RIPA plus PI. Proteins were resolved in $4-15 \%$ gradient SDSPAGE (Bio-Rad, Hercules, CA) and visualized with autoradiography.

Zebrafish injections and culture. Experiments and experimental procedures involving zebrafish were approved by the University of Iowa Ani- mal Care and Use Committee. Embryos were collected 10-20 min after natural matings. Plasmids were injected into the cytoplasm of singlecelled embryos using a PLI-90 picoinjector (Harvard Apparatus, Holliston, MA) and individually calibrated glass needles. Phenol red was added to plasmid solutions to monitor injections. For monitoring toxicity and inclusion formation of Q(n)-GFP proteins, $1 \mathrm{nl}$ of a $250 \mathrm{ng} / \mu$ l solution was injected. For double-plasmid injections, $1 \mathrm{nl}$ of solution consisting of $200 \mathrm{ng} / \mu \mathrm{l}$ polyQ and $400 \mathrm{ng} / \mu \mathrm{l} \mathrm{CHIP}$ was injected. Embryos were cultured at $28.5^{\circ} \mathrm{C}$ in standard system water supplemented with $2 \%$ penicillin and streptomycin. Embryos that completely lysed in their chorions were scored as dead (supplemental Fig. 1, www.jneurosci.org as supplemental material). This represented the overwhelming majority of embryos scored as dead. In cases in which embryos were severely malformed but not lysed, the presence of visible beating of the heart tube was used to determine live/dead status. Less than $10 \%$ of embryos scored as dead fell into this second category. Statistical significance in mortality was determined via a two-tailed Student's $t$ test, with $p<0.05$ considered significant.

In situ lysis assays. Cells expressing GFP-Q82-Htt were lysed $72 \mathrm{~h}$ after transfection by the addition of $1.25 \%$ SDS and $1.25 \%$ Triton X-100 in PBS. Images were collected after $3 \mathrm{~min}$ of detergent treatment. Fluorescence was quantitated by collecting three nonoverlapping images per well in each of two independent experiments. Pixel count was determined by highlighting all green pixels using the magic wand tool in Adobe Photoshop 6.0. Green pixels per image were determined using the histogram function. The average number of green pixels for cells transfected with GFP-Q82-Htt and empty vector was set at $100 \%$. Figure $2 B$ reports the average number of residual fluorescent pixels expressed relative to control vector cotransfections.

Primary neuronal culture. Cultures were derived from cerebri of embryonic day 16 wild-type B6C3F1/J mice (The Jackson Laboratory, Bar Harbor, ME) as described previously (Meberg and Miller, 2003), with minor modifications. Neurons were transfected using Lipofectamine Plus (Invitrogen) 2-4 d after plating. Statistically significant differences in sick/dead cells were determined via a two-tailed Student's $t$ test.

The vital dye exclusion assay was performed by adding $1.0 \%(\mathrm{w} / \mathrm{v})$ trypan blue (Sigma) dissolved in PBS to $1 \mathrm{ml}$ of culture media to achieve a final concentration of $0.01 \%$. Identical microscopic fields were imaged before and $3 \mathrm{~min}$ after the addition of trypan blue.

Mouse breeding. Experiments and experimental procedures involving mice were approved by the University of Iowa Animal Care and Use Committee. Mice were fed food and water ad libitum and maintained under $12 \mathrm{~h}$ light/dark lighting conditions. As HD mice became symptomatic, gruel was provided on the cage floor to supply adequate hydration and nutrition. N171-82Q HD transgenic mice were purchased from The Jackson Laboratory (B6/C3F1/J mixed background), and CHIP knockout mice were provided by Dr. C. Patterson (University of North Carolina, Chapel Hill, NC; 129/C57Bl6 mixed background) (Dai et al., 2003). HD transgenic male mice were bred to CHIP haploinsufficient $(+/-)$ female mice to produce $\mathrm{HD} \times \mathrm{CHIP}+/-$ offspring.

Tissue preparation and histochemistry. Mice were given an intraperitoneal injection of $200 \mu \mathrm{g} / \mathrm{g}$ ketamine and $20 \mu \mathrm{g} / \mathrm{g}$ xylazine. Transcardial perfusion of ice-cold $0.1 \mathrm{M}$ PBS, pH 7.4, was followed by perfusion with an ice-cold fixative containing $4 \%$ paraformaldehyde in PBS (PFA/PBS), $\mathrm{pH}$ 7.4. Brains were removed and immersed in PFA/PBS overnight at $4{ }^{\circ} \mathrm{C}$ and placed in a $30 \%(\mathrm{w} / \mathrm{v})$ sucrose PBS solution overnight at $4^{\circ} \mathrm{C}$ for cryoprotection. Brains were embedded in OCT media, and 30- $\mu$ m-thick coronal sections were cut using a cryostat. Free-floating sections were collected in $0.1 \mathrm{M}$ PBS for staining.

Immunofluorescence on free-floating sections was done by incubating sections overnight in primary antibodies: mouse EM48 antibody (1:250; provided by X.-J. Li, Emory University School of Medicine, Atlanta, GA) for $\mathrm{Htt}$ and anti-ubiquitin (1:200; Dako, Carpinteria, CA). Fluorescence was detected using Cy3- or Cy5-conjugated secondary antibodies (1:200) incubated for $2 \mathrm{~h}$ at room temperature. Blinded immunostaining and analysis of DARPP-32 (dopamine- and cAMP-responsive phosphoprotein of $32 \mathrm{kDa}$ ) was performed by peroxidase-based immunohistochemistry. Free-floating sections were incubated in $3 \% \mathrm{H}_{2} \mathrm{O}_{2}$, followed by DARPP-32 primary antibody (1:1000; $24 \mathrm{~h}$ at room temperature; Chemi- 
con, Temecula, CA). After incubation in biotinylated goat anti-rabbit secondary antibody (1: 200; $2 \mathrm{~h}$ at room temperature), sections were placed in an avidin-biotin HRP complex (ABC kit; $1 \mathrm{~h}$ at room temperature; Vector Laboratories, Burlingame, CA). Labeling was visualized using diaminobenzidine, each condition having an identical exposure time. High-power brightfield was visualized with a Zeiss Axioplan fluorescence microscope, and images were captured digitally with a Zeiss MRM AxioCam camera. Entire slides were scanned electronically for digital imaging, and images were assembled in Photoshop 6.0 (Adobe Systems).

Rotarod experiments. Rotarod testing was performed as described previously (Schilling et al., 1999), with minor modifications. Approximately 4-month-old (14-16 weeks) mice of each of the following genotypes were compared with age-matched, wild-type mice: HD, $\mathrm{CHIP}+/-, \mathrm{HD} \times \mathrm{CHIP}+/-$. Mice were tested on an accelerating rotarod device (Rota-Rod; Ugo Basile, Comerio VA, Italy). The speed was set to accelerate from 3 to $30 \mathrm{rpm}$ over the course of $5 \mathrm{~min}$. Mice were trained for $1 \mathrm{~d}$ before testing by running on the rotarod for two 5 min periods to familiarize them with the machine. Subsequent to training, three trials per day were performed over a $3 \mathrm{~d}$ period. Latency times were recorded when mice either fell from the rod or passively rotated around the rod at least two times in succession. Each mouse had at least 10 min of recovery time between trials. The data for each genotype were averaged and plotted.

\section{Results}

CHIP reduces aggregation and increases solubility of mutant polyQ protein

To test the hypothesis that CHIP modulates protein aggregation, we coexpressed mutant polyQ protein with wild-type CHIP (WT-CHIP) or mutant CHIP deleted of either its N-terminal TPR domain ( $\triangle$ TPR-CHIP) or its C-terminal E4/U-box domain ( $\Delta$ E4/U-box) (Connell et al., 2001; Meacham et al., 2001). Initially, we applied a widely used polyQ fragment (Onodera et al., 1997) containing a normal or expanded repeat (Q19 or Q71). The polyQ fragments are extremely stable proteins when fused to conventional GFP (our unpublished results); thus, we fused the polyQ domain to GFPu to more accurately simulate normal protein processing while retaining the desirable qualities of bright fluorescence and rapid aggregation (Fig. 1A) (Onodera et al., 1997; Bence et al., 2001).

Most Cos-7 cells expressing Q71-GFPu formed large juxtanuclear inclusions with little residual diffuse fluorescence, indicating that the polyQ protein had aggregated (Fig. $1 B$ ). In contrast, cells coexpressing WT-CHIP with Q71-GFPu had far fewer and smaller inclusions, with most of the GFP signal remaining diffuse. Consistent with these results, Western blot analysis showed that coexpression of WT-CHIP caused more Q71-GFPu to migrate as soluble monomer in the separating gel with less of the polyQ protein remaining in the stacking gel as insoluble, aggregated material (Fig. $1 C$ ). Expression of a $\triangle$ TPR-CHIP mutant, which cannot interact with chaperones, did not reduce aggregates (Fig. 1C). In contrast, expression of the $\Delta \mathrm{E} 4 / \mathrm{U}$-box mutant, which lacks E3 ligase activity, reduced inclusions and aggregates in a manner similar to WT-CHIP (Fig. 1C). The nonpathogenic fusion protein Q19-GFPu never formed aggregates, and its gel migration and protein levels were unchanged by coexpression of any form of CHIP (Fig. 1C). These results indicate that the cochaperone function of CHIP, mediated by its TPR domain, is required for suppression of polyQ aggregation. Its E3 ligase activity, however, appears to be dispensable.

We also tested whether CHIP could inhibit inclusion formation in differentiated PC-12 neural cells (Fig. 1D). polyQ protein expression is less robust in PC-12 cells than in Cos-7 cells, and inclusion formation is accordingly less pronounced. This allowed us to test CHIP activity against GFP fusion proteins with or without a degron. Coexpression of WT-CHIP markedly suppressed the number of inclusion-containing cells, whether they expressed Q71-GFPu (7.4\% of control levels) or the degron-less Q56-GFP (26.5\% of control levels). Again, coexpression of $\triangle \mathrm{TPR}-\mathrm{CHIP}$ did not suppress aggregation of either polyQ protein (Fig. 1D). These results show that CHIP is capable of reducing polyQ protein aggregation in differentiated neural cells and that this effect does not depend on the presence of a degron.

Subsequently, we tested the ability of CHIP to suppress aggregation of expanded polyQ in the context of the HD protein Htt. We cotransfected a plasmid encoding the first three exons of $\mathrm{Htt}$ fused to GFP (GFP-Q82-Htt) together with WT-CHIP or $\Delta$ TPR CHIP plasmids. GFP-Q82-Htt formed large cytoplasmic inclusions (Fig. 2A). Coexpression of CHIP with GFP-Q82-Htt resulted in fewer and smaller inclusions with greater diffuse fluorescence in the rare, remaining inclusion-positive cells (Fig. 2A). Consistent with this result, WT-CHIP increased the amount of GFP-Q82-Htt migrating as a soluble monomer on gels and decreased the amount of aggregated material retained in the stack (Fig. $2 B$ ). $\Delta$ TPR-CHIP again failed to suppress inclusion formation and aggregation (Fig. $2 B$ ).

To quantify Htt aggregation, we adopted an in situ detergent 


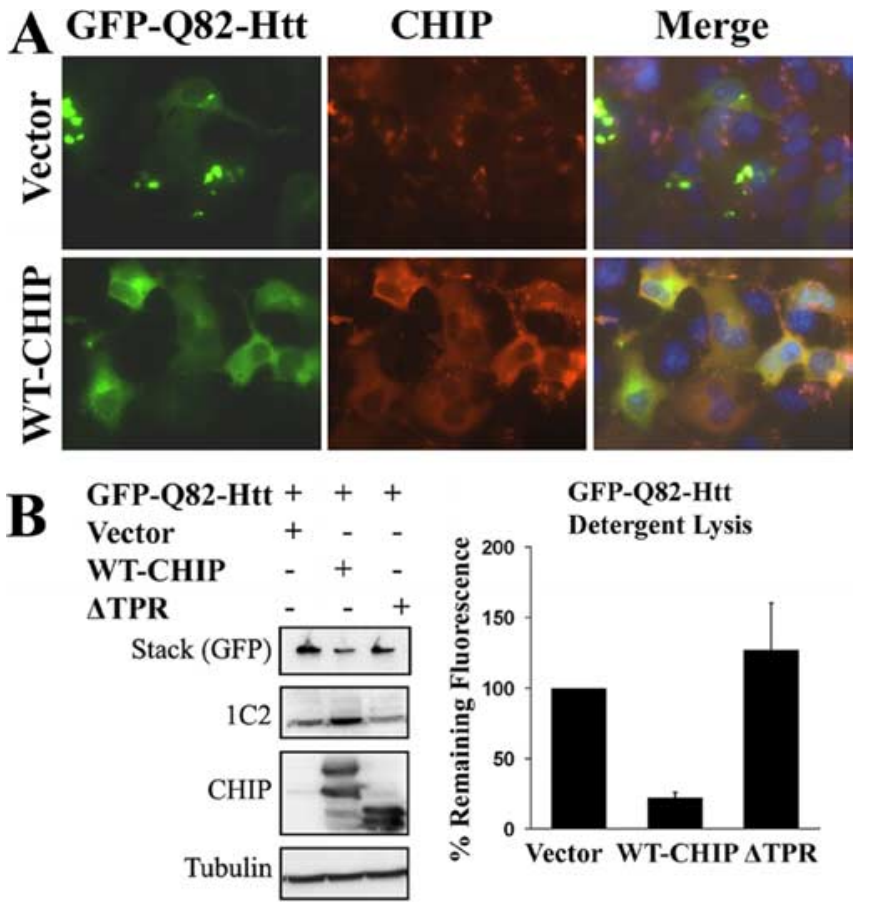

Figure 2. CHIP suppresses aggregation of the mutant $\mathrm{Htt}$ fragment. $A$, Immunofluorescence of Cos-7 cells showing expression and cellular distribution of GFP-082-Htt in the absence (top) or presence (bottom) of coexpressed WT-CHIP. The merged images show 4',6-diamidino-2phenylindole-stained nuclei in blue. $\boldsymbol{B}$, Western blot analysis of the GFP-082-Htt protein detected with $1 \mathrm{C} 2$ and GFP antibodies. Increased monomeric and decreased aggregated $\mathrm{Htt}$ are seen in the presence of WT-CHIP (left). The bar graph (right) shows quantitation of SDSresistant, GFP-082-Htt aggregates 3 min after detergent lysis. The percentage of residual GFP fluorescence is shown relative to control cells cotransfected with GFP-082-Htt and control vector (set at 100\%). The graph depicts the mean and SD of two independent experiments.

lysis technique. In this assay, fluorescence from soluble polyQGFP is quenched by the detergent, but fluorescence from aggregated, insoluble protein is not (Kazantsev et al., 1999). After detergent lysis, cells coexpressing WT-CHIP retained much less residual GFP fluorescence than cells cotransfected with $\Delta$ TPRCHIP or empty vector (Fig. $2 B$ right), confirming that CHIP reduced the formation of GFP-Q82-Htt aggregates.

From these cell-based studies, we conclude that CHIP suppresses the formation of insoluble aggregates by mutant polyQ proteins. This property of CHIP requires an intact TPR domain, suggesting that interactions between CHIP and chaperones increase cellular capacity to appropriately handle misfolded polyQ proteins.

Aggregate suppression by CHIP is independent of chaperone induction or enhanced degradation

Subsequently, we examined potential mechanisms by which CHIP reduces polyQ aggregation. One possible explanation is that CHIP, through its known interaction with HSF1, simply increases Hsp chaperone levels (Dai et al., 2003). Accordingly, we tested the ability of CHIP to induce a stress response and compared the results to those obtained with geldanamycin, a well documented inducer of the stress response. Geldanamycin is a chemical inhibitor of Hsp90 that upregulates HSF1 activity and induces a stress response (Sittler et al., 2001). We cotransfected cells with Q71-GFPu and either WT-CHIP or empty vector and treated cells with or without geldanamycin. Geldanamycin itself reduced aggregation of Q71-GFPu (Fig. 3A), consistent with a previous report (Sittler et al., 2001), and induced a mild stress
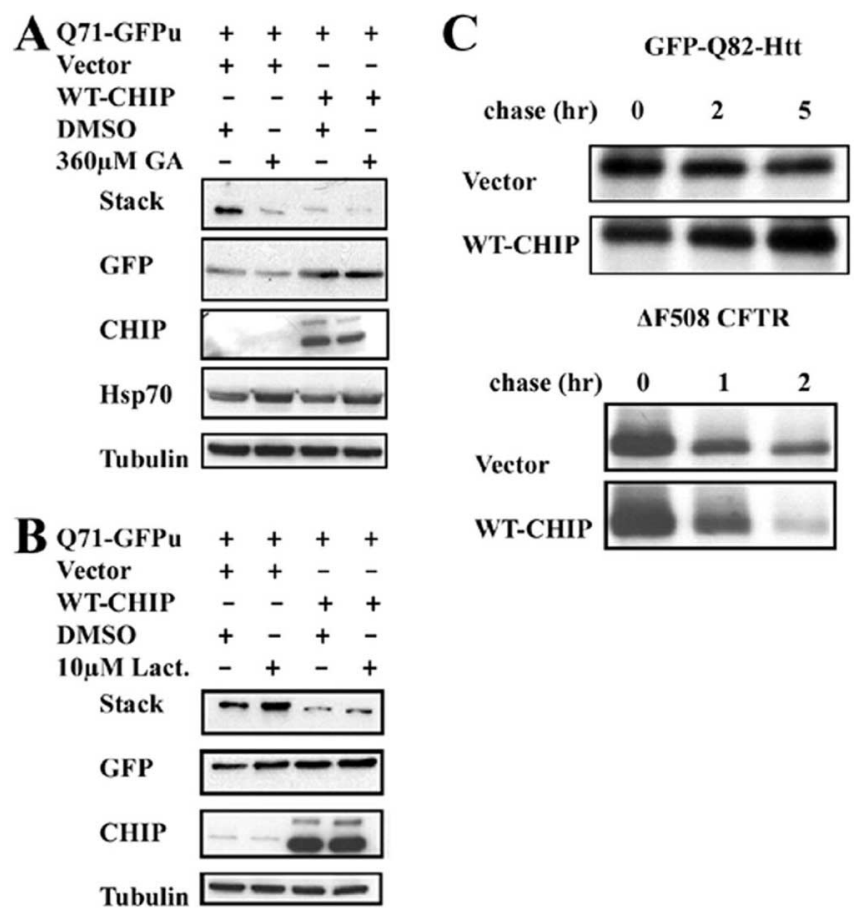

Figure 3. Solubilization of the mutant polyQ protein by CHIP occurs independent of chaperone induction or enhanced degradation. $\boldsymbol{A}$, Western blot analysis of Cos-7 cells cotransfected with Q71-GFPu and either WT-CHIP or empty vector. Cells were incubated with geldanamycin (GA) or carrier agent (DMSO) for $48 \mathrm{~h}$. B. Western blot analysis of Cos-7 cells cotransfected with Q71-GFPu and either WT-CHIP or empty vector. Cells were treated with lactacystin (Lact.) or DMSO for $30 \mathrm{~h}$ and harvested $48 \mathrm{~h}$ after transfection for Western blotting with the indicated antibodies (the stack was probed with anti-GFP antibody). C, Pulse/chase labeling experiments to assess degradation of GFP-Q82-Htt in the presence of CHIP. GFP-Q82-Htt degradation is not enhanced by coexpression of CHIP (top). In contrast, $\Delta$ F508 CFTR is degraded more rapidly when CHIP is coexpressed (bottom).

response exemplified by increased Hsp70 levels. Although CHIP also reduced aggregation in this assay, it did not induce Hsp70 under the same conditions (Fig. 3A). Moreover, there was no apparent synergy between CHIP and geldanamycin with respect to aggregate suppression or to Hsp70 induction (Fig. 3A). This suggests that CHIP does not suppress aggregation by inducing a stress response.

We next tested whether CHIP acted by increasing the rate of turnover of mutant polyQ proteins. We transfected cells with Q71-GFPu with or without WT-CHIP and treated cells with or without the proteasome inhibitor lactacystin (Fig. 3B). In the absence of coexpressed CHIP, polyQ aggregate formation was increased by lactacystin, consistent with previous reports (Chai et al. 1999a). Interestingly, CHIP suppressed polyQ aggregation even in the presence of this proteasome inhibitor (Fig. 3B). To directly measure protein turnover, we performed ${ }^{35} \mathrm{~S}$ methionine pulse/chase labeling in cells expressing GFP-Q82-Htt with or without WT-CHIP. CHIP did not increase the rate of Htt degradation, although it did enhance degradation of a well known substrate, cystic fibrosis transmembrane conductance regulator chloride channel (CFTR) (Fig. 3C) (Meacham et al., 2001). Based on these experiments, we conclude that enhanced degradation is not the primary route by which CHIP suppresses polyQ aggregate formation. Rather, this suppression likely involves enhanced Hsp70-dependent refolding or increased trapping of substrates in association with Hsp70. This is consistent with the previously reported effects of CHIP on folding of heatdenatured luciferase (Kampinga et al., 2003). 
CHIP rescues inclusion formation and toxicity in primary neurons

Given the key role of polyQ oligomerization in triggering toxicity (Sanchez et al., 2003), we suspected that the ability of CHIP to suppress aggregation might translate into an ability to suppress neurotoxicity. We tested this hypothesis in primary neuronal cultures. First, we confirmed by immunostaining and Western blot analysis that CHIP is expressed in primary neurons and adult mouse brain (data not shown). In murine cortical neurons transfected with Q71-GFPu, we observed large cytoplasmic and small neuritic inclusions with rare intranuclear inclusions (Fig. 4A, left). Microtubule-associated binding protein 2 (MAP2) staining confirmed the neuronal identity of transfected cells. In cells transfected with Q71-GFPu and empty vector, inclusions were often associated with rounded cell bodies, retracted neurites, and nuclear fragmentation (Fig. $4 A$, right). After coexpression of WT-CHIP, Q71-GFPu-expressing cells were much more likely to maintain a typical neuronal appearance with less frequent inclusions and nuclear fragmentation (Fig. 4A). CHIP coexpression resulted in a $60 \%$ reduction in the number of neurons having inclusions ( $25 \%$ of neurons transfected with Q71-GFPu and CHIP vs $63 \%$ of neurons transfected with Q71-GFPu alone) (Fig. 4B). Neither endogenous nor overexpressed CHIP colocalized to inclusions (data not shown). $\Delta$ TPR-CHIP again failed to suppress inclusion formation, confirming the importance of the TPR domain for suppression of aggregation in neurons.

Subsequently, we determined whether suppression of aggregation by CHIP resulted in decreased neuronal cell death. Cell morphology was examined under bright-field and fluorescent illumination. Cells with flattened cell bodies and intact GFP-filled neurites were scored as living, whereas rounded cells with retracted neurites or cells displaying an apoptotic, blebbed morphology were scored as sick/dead. (Cells that could not be unambiguously scored were scored as living.) As shown in Figure 4C, WT-CHIP conferred significant protection against polyQ toxicity (28\% reduction in sick/dead cells by $72 \mathrm{~h} ; p<0.02$ at both 48 and $72 \mathrm{~h}$ ), but $\Delta$ TPR-CHIP did not. To confirm the validity of our morphological criteria, we stained transfected neurons with trypan blue, a cell death detection dye that quenches GFP fluorescence in dead cells that are no longer able to exclude the dye (Fig. 4D). Consistent with our results in cell lines, overexpressed CHIP protected primary mammalian neurons from polyQ inclusion formation and toxicity in a manner dependent on the TPR domain of CHIP.

\section{Zebrafish model recapitulates features of polyQ disease}

To develop a rapid, vertebrate-based, in vivo assay for testing potential disease modifiers like CHIP, we explored the expression
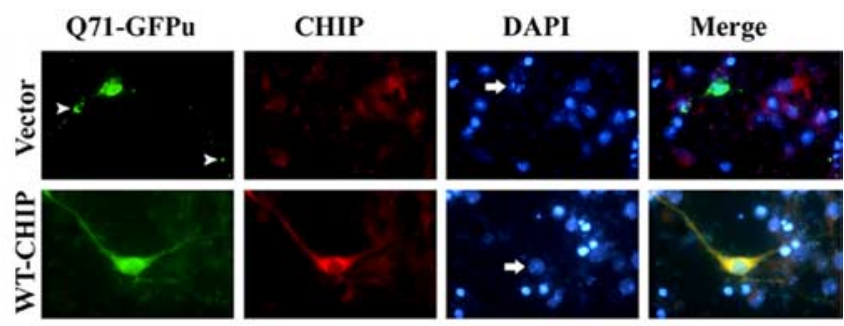

C

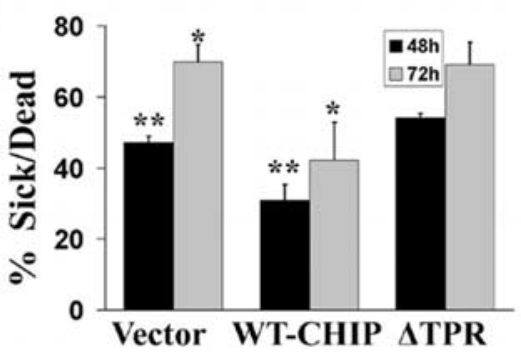$$
\Delta T P R
$$

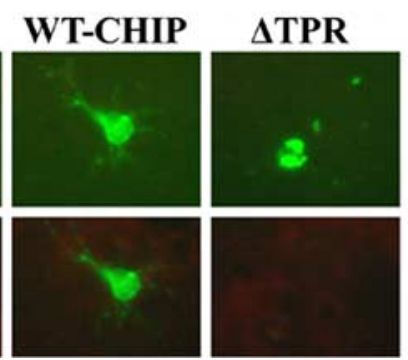

Figure 4. CHIP rescues poly 0 aggregation and toxicity in primary neurons. $A$, Left, A representative transfected cortical neuron, verified by MAP2 immunostaining (red), expressing Q71-GFPu (green) $48 \mathrm{~h}$ after transfection. Both smaller neuritic inclusion phenylindole-stained nucleus). Right, Immunofluorescent staining of representative neurons cotransfected with Q71-GFPu and vector or WT-CHIP. The arrows point to nuclei of transfected cells, and the arrowheads point to inclusions. B, Quantitation tion as having no inclusions or one or more inclusions. The bars depict the mean and SD of four independent experiments. Confirmation of morphological criteria by trypan blue (TB) exclusion. Neurons transfected with Q71-GFPu and the indicated CHIP variants were imaged before (Pre-TB) and 3 min after (Post-TB) treatment with $0.01 \%$ TB solution. Dead cells, which are unable to exclude TB, show rapid quenching of fluorescence.

of polyQ proteins in zebrafish. We first tested the effect of expressing various polyQ fusion proteins in zebrafish embryos. After fertilization, single-celled embryos were injected with plasmids encoding normal or expanded polyQ tracts fused to GFP (Fig. 1A). Developing embryos were monitored at 24 and $48 \mathrm{~h}$ for toxicity and aggregation of the polyQ protein. At $24 \mathrm{~h}$, there were clear differences in the survival and morphology of embryos expressing pathogenic versus nonpathogenic polyQ tracts (Fig. $5 A$ ). Embryos expressing polyQ proteins with repeats below or near the disease threshold (Q19-GFP, Q35-GFP) were primarily normal in appearance. There was slight developmental delay attributable to the injection procedure itself, but death was only slightly higher than in uninjected sibling embryos (Fig. $5 B$ ). In contrast, embryos expressing Q56-GFP or Q80-GFP were morphologically abnormal, displaying developmental delay and gross abnormalities in body plan and differentiation (Fig. 5A). There were also visible patches of brownish, opaque tissue containing rounded cells indicative of cell death. These cells stained with the cell death marker acridine orange (supplemental Fig. 1, www.jneurosci.org 

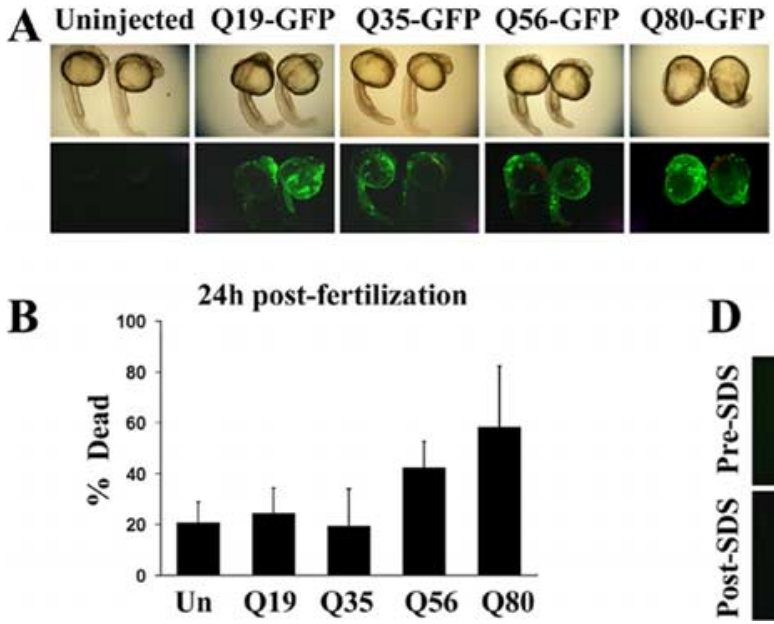
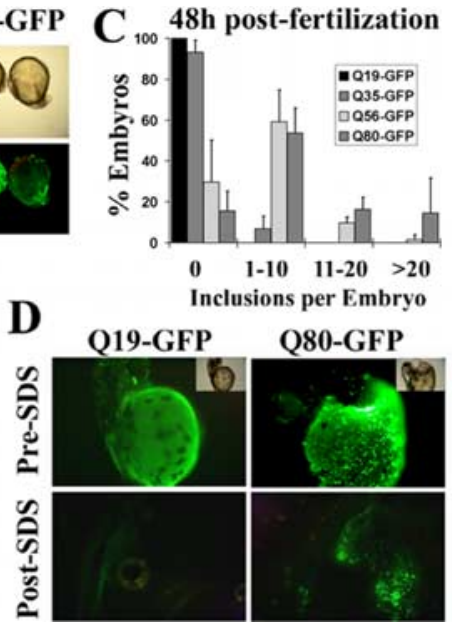

Figure 5. Modeling features of polyQ disease in zebrafish. A, Bright-field (top) and fluorescent (bottom) images of zebrafish embryos, $24 \mathrm{~h}$ old, expressing the indicated polyQ-GFP fusions. In each panel, the embryo pairs represent a higher-expressing and a lower-expressing embryo. Note the poly $Q$ length-dependent appearance of decreased embryo length and poorly differentiated tissues resulting in dysmorphic embryos. $\boldsymbol{B}$, Quantitation of dead embryos $24 \mathrm{~h}$ after fertilization (left), after injection at the one-cell stage with plasmids encoding the indicated polyQ-GFP fusions. Increasing polyQ length is associated with increased lethality. The bars depict the mean and SD of five independent injections ( $>100$ animals analyzed per condition). Un, Uninjected. C, Quantitation of inclusion formation in surviving embryos. Embryos were scored by a blinded observer as having 0, 1-10, 11-20, or $>20$ inclusions per embryo. The bars represent the mean and SD of four independent injections ( $>50$ animals were analyzed per condition). D, In situ lysis of embryos, $48 \mathrm{~h}$ old, expressing the indicated polyQ-GFP fusions. Embryos are shown under fluorescent or bright-field illumination (inset) before (Pre-SDS) or 5 min after (Post-SDS) lysis with denaturing detergent. Fluorescence from soluble Q19-GFP is rapidly quenched after detergent lysis (left), whereas aggregated Q80-GFP is resistant to denaturation and retains fluorescence under these conditions.
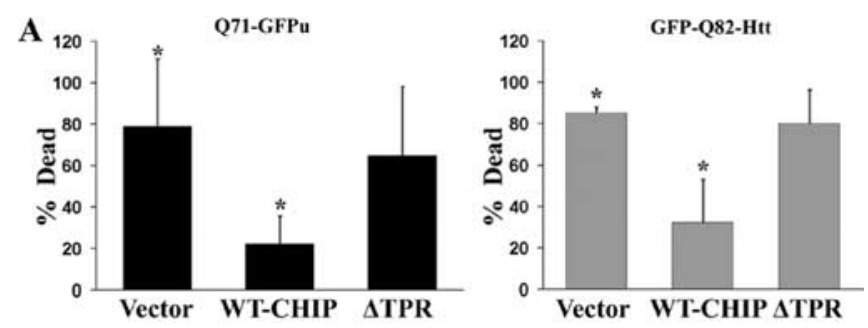

B

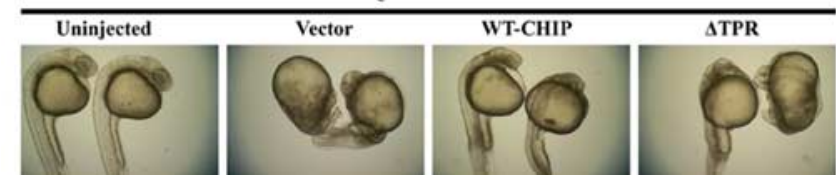

Figure 6. CHIP suppresses poly $\mathrm{Q}$ toxicity in developing zebrafish. $\boldsymbol{A}, \mathrm{Q}$ Quantitation of embryo death $24 \mathrm{~h}$ after fertilization, after injection at the one-cell stage of Q71-GFPu (left) or GFP-Q82Htt (right) together with the indicated CHIP plasmids. Death is decreased by coexpression of WT-CHIP but not of mutant CHIP-DTPR. The bars depict the mean and SD of four independent injections for Q71-GFPu (>120 total animals analyzed) and three independent injections for GFP-082-Htt ( $>80$ total animals analyzed). ${ }^{*} p<0.02$, significant difference between groups. $\boldsymbol{B}$, Representative bright-field images of 24-h-old survivors coinjected with Q71-GFPu and the indicated empty vector, WT-CHIP, or mutant CHIP. WT-CHIP partially restores normal embryo length, optical clarity, and development of head, tail, and somite structures.

as supplemental material). Death was elevated in Q56-GFPexpressing embryos and, in the Q80-GFP-injected group, reached twice the level observed for Q19-GFP (Fig. 5B).

Inclusion formation by polyQ proteins in zebrafish embryos correlated with repeat length. At $48 \mathrm{~h}$, surviving embryos were scored for the number of inclusion-containing cells per animal (Fig. 5C). The GFP-polyQ protein was diffusely distributed in embryos expressing polyQ repeats of nonpathogenic length. For example, Q19GFP-expressing embryos never contained inclusions, and only $7 \%$ of Q35-GFP-expressing embryos had any inclusions. In contrast, Q56- and Q80-GFPexpressing embryos had one or more inclusions in $\sim 70$ and $85 \%$ of animals, respectively. Q80-GFP embryos also displayed many more inclusions per animal (Fig. 5C).

To test whether these visible inclusions represented insoluble aggregates (Kazantsev et al., 1999), we developed an in situ lysis assay to assess the detergent solubility of inclusions (Fig. 5D). This assay showed that pathogenic polyQ proteins form insoluble aggregates that can be monitored in developing fish.

We conclude that embryonic zebrafish recapitulate two important features of polyQ disease: repeat length-dependent toxicity and inclusion/aggregate formation. The repeat length for onset of pathology in zebrafish embryos parallels the threshold for polyQ length toxicity seen in human disease (Zoghbi and Orr, 2000). Moreover, the results with detergent lysis suggest that the sequential process of misfolding, oligomerization, and aggregation occurs in zebrafish in a manner similar to that observed in disease tissue and other experimental systems (Sanchez et al., 2003). These results encouraged us to use zebrafish as a simple, efficient in vivo model in which to test the effects of CHIP on polyQ toxicity.

\section{CHIP rescues polyQ toxicity in zebrafish}

We coinjected zebrafish embryos with plasmids expressing mutant polyQ proteins (Q71-GFPu and GFP-Q82-Htt) and empty vector, WT-CHIP, or $\triangle$ TPR-CHIP. Embryos injected with mutant polyQ proteins and empty vector died at a high rate (Fig. $6 A$ ). Most surviving embryos were severely disturbed in their overall body pattern, showed developmental delay, and had prominent patches of dead or dying cells (Fig. $6 \mathrm{~B}$ ). Coexpression of WT-CHIP rescued polyQ-mediated death at $24 \mathrm{~h}$, with the resultant embryos showing improved morphology, although some developmental delay and occasional patches of dead and dying cells were still observed (Fig. 6A,B). $\Delta$ TPR-CHIPcoexpressing embryos died at the same frequency as polyQ protein-expressing embryos coinjected with control vector and showed similar morphological disturbances among survivors (Fig. 6A,B). Coexpression of CHIP decreased toxicity of both a generic polyQ-containing fragment and a pathogenic Htt fragment in zebrafish embryos. Thus, the ability of CHIP to reduce aggregation and toxicity of mutant polyQ proteins in cell lines and primary neurons correlates with suppression of toxicity in vivo.

\section{CHIP haploinsufficiency accelerates polyQ disease in a mouse model of HD}

The above results suggested that endogenous CHIP plays an important role in buffering misfolded polyQ-induced toxicity in neurons. If CHIP assists in the neuronal handling of mutant polyQ protein, then reducing levels of CHIP would be predicted to exacerbate polyQ disease. To directly test this in vivo, we placed the N171-Q82 HD transgenic mouse model (Schilling et al., 
1999) onto a CHIP haploinsufficient background (Dai et al., 2003).

In N171-Q82 mice (HD mice), the prion promoter drives neuronal expression of the same Htt fragment used in our cell culture and zebrafish studies (although minus the GFP tag). In this mouse model, ubiquitin-positive inclusions can be detected in several brain regions, most prominently in the cortex and cerebellum. These mice fail to gain weight and progressively display an HD-like motor phenotype characterized by tremor, gait disturbance, abnormal clasping, and hypoactivity leading to premature death between 5 and 6 months of age. Progressive motor abnormalities in this model of HD most likely reflect polyQ-induced neuronal dysfunction rather than neuronal cell death, because neuronal loss is not evident (Schilling et al., 1999).

We chose to cross HD mice to CHIP haploinsufficient $(+/-)$ mice rather than to CHIP knock-out $(-/-)$ mice because the latter, in our hands, are not recovered at Mendelian ratios and are fragile, being highly susceptible to heat shock and other stressors (Dai et al., 2003). In contrast, $\mathrm{CHIP}+/-$ mice are indistinguishable from wild-type littermates in their gross appearance, weight, behavior, and life span (Fig. 7 and data not shown). In $\mathrm{CHIP}+/-$ mice, a reduction in the brain levels of CHIP protein was confirmed by Western blot analysis (Fig. 7A).

The course of disease in HD transgenic mice with CHIP haploinsufficiency $(\mathrm{HD} \times \mathrm{CHIP}+/-)$ differed significantly from HD transgenic mice with normal CHIP activity (HD), as well as from WT and CHIP $+/-$ mice. Mice of all four tested genotypes $(\mathrm{HD}, \mathrm{HD} \times \mathrm{CHIP}+/-, \mathrm{CHIP}+/-$, and $\mathrm{WT}$ mice) appeared normal until 7-9 weeks of age. By 10-14 weeks, however, $\mathrm{HD} \times \mathrm{CHIP}+/-$ mice displayed prominent kyphosis, poor grooming, tremor at rest and with activity, unsteady gait affecting the hindlimbs primarily, and marked hypoactivity (Fig. $7 B$, left). After tail suspension, $\mathrm{HD} \times \mathrm{CHIP}+/-$ mice clasped both the frontlimbs and hindlimbs and would not release this posture spontaneously (Fig. $7 B$, right). In contrast, age- and sexmatched HD mice displayed only a slight degree of open-field hypoactivity, mild action tremor, and occasional, reversible clasping (mainly of the forelimbs) without other symptoms (Fig. $7 B)$. Intriguingly, $\mathrm{HD} \times \mathrm{CHIP}+/-$ males had the most severe phenotype, developing motor abnormalities 2-4 weeks earlier than females. After onset, the phenotype of $\mathrm{HD} \times \mathrm{CHIP}+/-$ mice progressed rapidly to death over a $2-4$ week period. By 20 weeks, only $27 \%$ of $\mathrm{HD} \times \mathrm{CHIP}+/-$ remained alive, in contrast to $70 \%$ of $\mathrm{HD}$ mice and $100 \%$ of WT and CHIP $+/-$ mice (Fig. 7C).

To further characterize the motor phenotype of these mice, we performed rotarod analysis at 14-16 weeks of age. HD $\times$ $\mathrm{CHIP}+/-$ mice were very fragile at this stage; several died soon after the first rotarod training session. The analyzed cohort thus
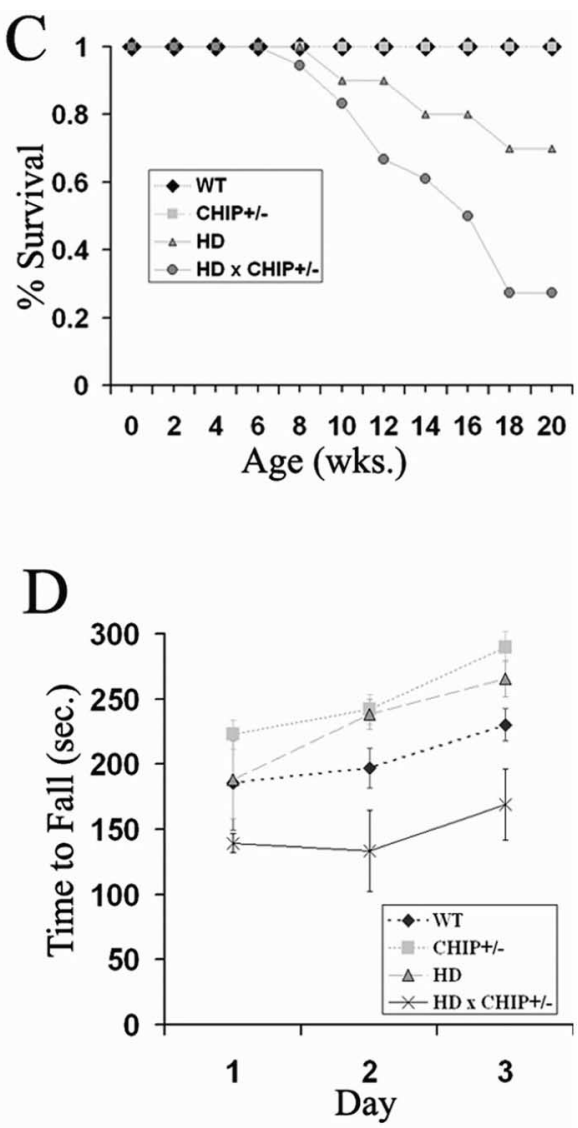

Figure 7. CHIP haplosufficiency accelerates the phenotype of HD transgenic mice. $\boldsymbol{A}$, Top, Western blot showing CHIP levels in were derived. The inactivated allele $(K / 0)$ migrates more slowly than the WT allele because of replacement of the first three exons with the neomycin cassette (Dai et al., 2003). B , Representative images of 15-week-old female mice of the indicated genotypes few steps and could not release clasping posture during tail suspension. C, Survival analysis for mice of the indicated genotypes ( $n=7 \mathrm{WT}, 10 \mathrm{CHIP}+/-, 10 \mathrm{HD}$, and $18 \mathrm{HD} \times \mathrm{CHIP}+/-$ ). wks., Weeks. D, Accelerating rotarod analysis for 14- to 15-week-0ld female mice of the indicated genotypes ( $n=4 \mathrm{WT}, 3 \mathrm{CHIP}+/-, 5 \mathrm{HD}, 3 \mathrm{HD} \times(\mathrm{HIP}+/-)$. sec., Seconds.

represents only those animals well enough to complete testing. Nevertheless, even these less overtly affected $\mathrm{HD} \times \mathrm{CHIP}+/-$ mice consistently performed worse than all other genotypes on the accelerating rotarod (Fig. 7D).

We then compared the distribution and intensity of Htt inclusions in HD mice versus HD mice with CHIP haploinsufficiency. Immunostaining of brain sections with EM48 and anti-ubiquitin antibodies revealed an increase in $\mathrm{Htt}$ inclusions in $\mathrm{HD} \times$ $\mathrm{CHIP}+/-$ mice, most notably in the cerebellar granule cell layer (Fig. 8A). An increase in diffuse nuclear localization of the $\mathrm{Htt}$ fragment was also noted in the hippocampus of $\mathrm{HD} \times \mathrm{CHIP}+/-$ mice (Fig. $8 \mathrm{~A}$ ). This result is consistent with data obtained in transfected primary neurons, in which expression of the expanded polyQ-GFP fragment in CHIP-deficient neurons resulted in increased numbers of inclusion-containing cells (data not shown). Htt inclusions were heavily ubiquitinated in both $\mathrm{HD}$ and $\mathrm{HD} \times \mathrm{CHIP}+/-$ brains (Fig. $8 \mathrm{~A}$ ), indicating that ubiquitination activity is not globally impaired in neurons missing a single CHIP allele.

Analysis of the anatomical integrity of $\mathrm{HD} \times \mathrm{CHIP}+/-$ brain sections stained with hematoxylin and eosin revealed no gross brain tissue or neuronal cell loss compared with WT, CHIP +/-, 


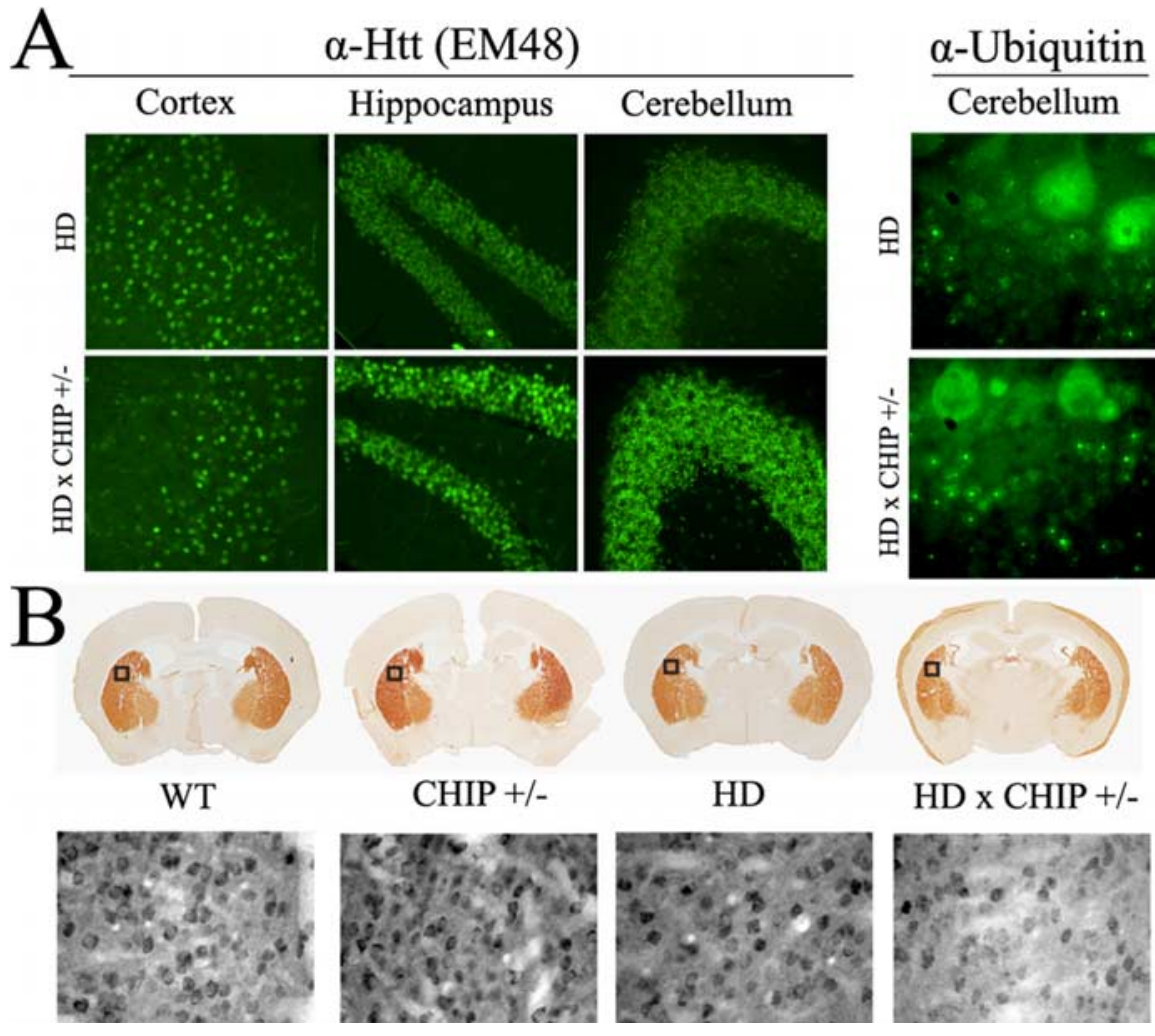

Figure 8. Histological analysis of HD mice. $A$, Left, Low-power images of EM48 immunostaining of 11-week-old male HD (top) and $\mathrm{HD} \times \mathrm{CHIP}+/-$ mice (bottom). In HD mice at this age, inclusions are rare in the cortex and hippocampus but prevalent in the granule cell layer of the cerebellum. In HD $\times$ CHIP $+/-$ mice, increased nuclear accumulation of the Htt fragment is evident in the hippocampus, and inclusions are more abundant in the cerebellar granule cell layer. Right, High-power images showing ubiquitin immunoreactivity in the cerebellum. The large, diffusely fluorescent cells at the top of each image are Purkinje cells. Inclusions in granule cells, which are observed both in $\mathrm{HD}$ and in $\mathrm{HD} \times \mathrm{CHIP}+/-$ mice, are ubiquitinated. $\boldsymbol{B}$, Representative DARPP-32 staining of the striatum in mice of the indicated genotypes. The boxes indicate the areas also shown at higher magnification. Higher-power images demonstrate that neurons in the striatum of $\mathrm{HD} \times \mathrm{CHIP}+\mathrm{I}-$ mice stain less intensely for DARPP-32 than do neurons in the other genotypes.

or HD mouse brain sections (data not shown). In contrast, immunohistochemical analysis revealed a reduction in the levels of the DARPP-32 in the striatum of $\mathrm{HD} \times \mathrm{CHIP}+/-$ mice compared with HD mice (Fig. $8 B$, top). A progressive loss in striatal DARPP-32 immunoreactivity has been linked previously to nigro-striatal dysfunction in mouse models of HD (Bibb et al., 2000; van Dellen et al., 2000). In agreement with our gross tissue analysis, the decrease in striatal DARPP-32 staining in $\mathrm{HD} \times$ $\mathrm{CHIP}+/-$ mice appeared to result from reduced neuronal staining rather than overt cell loss (Fig. $8 \mathrm{~B}$, bottom). In summary, we find that CHIP haploinsufficiency exacerbates and accelerates the neuronal dysfunction and behavioral phenotype displayed by N171-Q82 HD mice.

\section{Discussion}

Using complementary cellular and animal models, we have demonstrated that CHIP is an important component of the neuronal QC machinery. In the various model systems described here, CHIP levels determined the cellular ability to withstand the insults of polyQ aggregation and toxicity. Together, our results lead to a better understanding of the role of QC in polyQ disease pathogenesis and suggest potential avenues for therapy for this incurable group of neurodegenerative disorders.

Certain lines of evidence suggest that the two central arms of QC, molecular chaperones, and the UPP are taxed beyond physiological capacity in polyQ diseases (Bence et al., 2001; Venkatra- man et al., 2004). In light of this, numerous components of the QC machinery have been manipulated in an effort to reduce polyQ toxicity. For example, overexpressing Hsp chaperones consistently shows benefit in various model systems (Cummings et al., 1998; Chai et al., 1999b; Warrick et al., 1999; Carmichael et al., 2000; Kazemi-Esfarjani and Benzer, 2000; Wyttenbach et al., 2002). Yet in mouse models of disease, crosses to Hsp70overexpressing mice have resulted in, at best, a modest therapeutic benefit (Cummings et al., 2001; Hansson et al., 2003; Hay et al., 2004). Thus, in the current study, we investigated another promising component of QC, CHIP, to further define the elements of protein QC involved in polyQ neurodegenerative disease that might provide molecular targets for therapy.

The flexible and versatile QC functions of CHIP made it a particularly attractive target. Indeed, CHIP has been shown previously to influence the modification and turnover of several proteins central to other neurodegenerative conditions characterized by protein misfolding and aggregation (Imai et al., 2002; Petrucelli et al., 2004; Shimura et al., 2004; Jana et al., 2005). It was recently reported that CHIP facilitated ubiquitination and degradation of polyQ proteins and that this process was enhanced by overexpressing Hsc70 (Jana et al., 2005). Our results instead suggest that CHIP acts primarily to enhance the neuronal capacity to maintain polyQ proteins in a soluble, nonaggregated state. It does so in a manner requiring an intact TPR domain, the region through which CHIP interacts with Hsp70 and Hsc70. In contrast, based on our studies in transfected cells, CHIP did not require an intact ubiquitin ligase domain. Although our results do not rule out a role for the ubiquitin ligase activity of CHIP, they do suggest that chaperone interactions are likely to be critically important to its suppressor activity.

CHIP participates in triage decisions for specific substrate proteins (Connell et al., 2001). In our hands, CHIP did not facilitate degradation of the polyQ protein despite its known E3 ligase activity. It was originally described as a cochaperone that converts Hsp70 activity from substrate folding to degradation. For example, for CFTR and several other substrates (Connell et al., 2001; Meacham et al., 2001), CHIP stimulates ubiquitination, either directly through its E3 ligase activity or in cooperation with other ubiquitin ligases. CHIP does not, however, enhance degradation of all substrates. For instance, CHIP has no effect on the degradation of apolipoprotein B48, luciferase, or, in one study, the polyQ disease protein ataxin-3 (Meacham et al., 2001; Kampinga et al., 2003; Matsumoto et al., 2004). In the case of luciferase, even inducing misfolding of the protein by heat denaturation does not enhance its degradation by CHIP. Instead, CHIP increases Hsp70-dependent refolding of luciferase by inhibiting the ATP hydrolysis cycle of Hsp70 (Ballinger et al., 1999; Kampinga et al., 2003). ATP-bound Hsp70 has an increased substrate on-rate that 
increases overall substrate loading. Therefore, in the presence of increased CHIP, a greater fraction of cellular Hsp70 is bound to nascent polypeptide chains (Kampinga et al., 2003). We suggest that CHIP, through this action, enhances polyQ protein folding by increasing the probability that the misfolded protein is bound to chaperones and eventually processed through multiple rounds of the chaperone cycle. Increased binding of Hsp70 to the surface of misfolded polyQ proteins would also be expected to retard oligomerization, which is postulated to be a key step in polyQ toxicity and aggregation (Sanchez et al., 2003). Although our results with polyQ proteins are consistent with one of the known functions of CHIP, they suggest that the role of CHIP in QC is quite complex, participating in differing aspects of protein triage depending on the specific substrate.

To extend our cell-based studies of CHIP, we turned to zebrafish as a fast and efficient vertebrate model system. Zebrafish have only recently been explored as a model for neurodegenerative diseases (Rubinstein, 2003). Our study is the first to use zebrafish to model features of polyQ disease. We show that embryonic zebrafish replicate two features central to the human disease: polyQ length-dependent toxicity and aggregation. Although these features are also readily recapitulated in other model systems, zebrafish embryos offer certain advantages for modeling polyQ disease: they develop rapidly and externally, can be produced quickly in large numbers, and are transparent, permitting direct analysis of organs, tissues, and fluorescently tagged proteins. In addition, pathways and components of protein QC have been identified that are conserved from zebrafish to humans, including an HSF1-dependent stress response and a zebrafish ortholog of human CHIP (Wang et al., 2001; Strausberg et al., 2002). Antisense morpholinos can efficiently knock down expression of zebrafish genes, raising the possibility of studying candidate suppressor and enhancer genes (Nasevicius and Ekker, 2000). Finally, a variety of tissue-specific promoters allow targeted transgene expression to select populations of brain cells. For example, using the neural-specific GATA2 promoter (Meng et al., 1997) to drive GFP-polyQ expression, we have observed aggregation in a subset of neurons in the developing zebrafish brain (V. M. Miller, M. R. Rebagliati, and H. L. Paulson, unpublished results). These intrinsic advantages of zebrafish, coupled with the proof of principle demonstrated here, should encourage their use as a simple, efficient system in which to model neurodegenerative disease mechanisms in a living vertebrate. Taking full advantage of this simple vertebrate as a model for polyQ disease, however, will require the development of inducible transgenic zebrafish systems that manifest in the nervous system.

Growing experimental evidence implicates failures of protein QC in the pathogenesis of polyQ diseases. To our knowledge, however, our cross of HD mice to CHIP haploinsufficient mice is only the second example in which impairment of a specific QC component has been shown to worsen the polyQ disease phenotype in mammals in vivo. The first such case was the illustration that SCA1 mice showed enhanced degeneration when placed on a background deficient in the E6AP ubiquitin ligase (Cummings et al., 1999). The proteins most closely related to CHIP evolutionarily have not been identified as modifiers of polyQ aggregation in yeast or Caenorhabditis elegans screens; thus, it is striking that inactivation of one allele in mammals markedly accelerates the phenotype in an HD mouse model. This result likely reflects the particularly sensitive role that protein QC plays in mammalian neurons.

Although our data collectively suggest that CHIP acts in concert with chaperones to directly mitigate polyQ toxicity, CHIP could also act indirectly. For example, CHIP regulates the degradation of $\mathrm{p} 53$, a protein recently implicated in HD pathogenesis (Bae et al., 2005). Reduced CHIP levels in neurons could result in increased levels of p53 (or other substrates), thereby accelerating the disease phenotype. We suspect that CHIP participates at a crucial juncture in the pathway by which neurons handle mutant polyQ proteins, such that compromise of this process initiates a cascade of dysfunction severe enough to accelerate death of the animal. For this reason, the $\mathrm{HD} \times \mathrm{CHIP}+/-$ mouse provides a unique model in which to study the essential elements of protein QC that characterize the neuronal response to mutant polyQ proteins. CHIP and the proteins with which it associates can now be investigated as possible therapeutic targets in HD and other polyQ diseases.

In summary, our studies provide evidence that CHIP modulates aggregation and toxicity of polyQ disease proteins. We have used a variety of complementary approaches to evaluate the effects of CHIP, beginning in immortalized cell culture, followed by confirmatory studies in primary neurons, zebrafish, and genetically modified mice. This tiered approach offers a systematic and rigorous method for evaluating future candidate modifiers. The fact that beneficial effects of increased CHIP activity were observed across several model systems strengthens its potential as a therapeutic target in neurodegenerative disease. The profound phenotypic effects caused by CHIP haploinsufficiency in an HD mouse model also raise interesting mechanistic questions about the role of CHIP and other multifunctional proteins in protein QC.

\section{References}

Bae BI, Xu H, Igarashi S, Fujimuro M, Agrawal N, Taya Y, Hayward SD, Moran TH, Montell C, Ross CA, Snyder SH, Sawa A (2005) p53 mediates cellular dysfunction and behavioral abnormalities in Huntington's disease. Neuron 47:29-41.

Ballinger CA, Connell P, Wu Y, Hu Z, Thompson LJ, Yin LY, Patterson C (1999) Identification of CHIP, a novel tetratricopeptide repeatcontaining protein that interacts with heat shock proteins and negatively regulates chaperone functions. Mol Cell Biol 19:4535-4545.

Bence NF, Sampat RM, Kopito RR (2001) Impairment of the ubiquitinproteasome system by protein aggregation. Science 292:1552-1555.

Berke SJ, Paulson HL (2003) Protein aggregation and the ubiquitin proteasome pathway: gaining the UPPer hand on neurodegeneration. Curr Opin Genet Dev 13:253-261.

Bibb JA, Yan Z, Svenningsson P, Snyder GL, Pieribone VA, Horiuchi A, Nairn AC, Messer A, Greengard P (2000) Severe deficiencies in dopamine signaling in presymptomatic Huntington's disease mice. Proc Natl Acad Sci USA 97:6809-6814.

Carmichael J, Chatellier J, Woolfson A, Milstein C, Fersht AR, Rubinsztein DC (2000) Bacterial and yeast chaperones reduce both aggregate formation and cell death in mammalian cell models of Huntington's disease. Proc Natl Acad Sci USA 97:9701-9705.

Chai Y, Koppenhafer SL, Shoesmith SJ, Perez MK, Paulson HL (1999a) Evidence for proteasome involvement in polyglutamine disease: localization to nuclear inclusions in SCA3/MJD and suppression of polyglutamine aggregation in vitro. Hum Mol Genet 8:673-682.

Chai Y, Koppenhafer SL, Bonini NM, Paulson HL (1999b) Analysis of the role of heat shock protein (Hsp) molecular chaperones in polyglutamine disease. J Neurosci 19:10338-10347.

Chan HY, Warrick JM, Andriola I, Merry D, Bonini NM (2002) Genetic modulation of polyglutamine toxicity by protein conjugation pathways in Drosophila. Hum Mol Genet 11:2895-2904.

Connell P, Ballinger CA, Jiang J, Wu Y, Thompson LJ, Hohfeld J, Patterson C (2001) The co-chaperone CHIP regulates protein triage decisions mediated by heat-shock proteins. Nat Cell Biol 3:93-96.

Cummings CJ, Mancini MA, Antalffy B, DeFranco DB, Orr HT, Zoghbi HY (1998) Chaperone suppression of aggregation and altered subcellular proteasome localization imply protein misfolding in SCA1. Nat Genet 19:148-154.

Cummings CJ, Reinstein E, Sun Y, Antalffy B, Jiang Y, Ciechanover A, Orr 
HT, Beaudet AL, Zoghbi HY (1999) Mutation of the E6-AP ubiquitin ligase reduces nuclear inclusion frequency while accelerating polyglutamine-induced pathology in SCA1 mice. Neuron 24:879-892.

Cummings CJ, Sun Y, Opal P, Antalffy B, Mestril R, Orr HT, Dillmann WH, Zoghbi HY (2001) Over-expression of inducible HSP70 chaperone suppresses neuropathology and improves motor function in SCA1 mice. Hum Mol Genet 10:1511-1518.

Cyr DM, Hohfeld J, Patterson C (2002) Protein quality control: U-boxcontaining E3 ubiquitin ligases join the fold. Trends Biochem Sci 27:368-375.

Dai Q, Zhang C, Wu Y, McDonough H, Whaley RA, Godfrey V, Li HH, Madamanchi N, Xu W, Neckers L, Cyr D, Patterson C (2003) CHIP activates HSF1 and confers protection against apoptosis and cellular stress. EMBO J 22:5446-5458.

Fernandez-Funez P, Nino-Rosales ML, de Gouyon B, She WC, Luchak JM, Martinez P, Turiegano E, Benito J, Capovilla M, Skinner PJ, McCall A, Canal I, Orr HT, Zoghbi HY, Botas J (2000) Identification of genes that modify ataxin-1-induced neurodegeneration. Nature 408:101-106.

Hansson O, Nylandsted J, Castilho RF, Leist M, Jaattela M, Brundin P (2003) Overexpression of heat shock protein 70 in R6/2 Huntington's disease mice has only modest effects on disease progression. Brain Res 970:47-57.

Hartl FU, Hayer-Hartl M (2002) Molecular chaperones in the cytosol: from nascent chain to folded protein. Science 295:1852-1858.

Hay DG, Sathasivam K, Tobaben S, Stahl B, Marber M, Mestril R, Mahal A, Smith DL, Woodman B, Bates GP (2004) Progressive decrease in chaperone protein levels in a mouse model of Huntington's disease and induction of stress proteins as a therapeutic approach. Hum Mol Genet 13:1389-1405.

Imai Y, Soda M, Hatakeyama S, Akagi T, Hashikawa T, Nakayama KI, Takahashi R (2002) CHIP is associated with Parkin, a gene responsible for familial Parkinson's disease, and enhances its ubiquitin ligase activity. Mol Cell 10:55-67.

Jana NR, Dikshit P, Goswami A, Kotliarova S, Murata S, Tanaka K, Nukina N (2005) Co-chaperone CHIP associates with expanded polyglutamine protein and promotes their degradation by proteasomes. J Biol Chem 280:11635-11640.

Jiang J, Ballinger CA, Wu Y, Dai Q, Cyr DM, Hohfeld J, Patterson C (2001) CHIP is a U-box-dependent $\mathrm{E} 3$ ubiquitin ligase: identification of $\mathrm{Hsc} 70$ as a target for ubiquitylation. J Biol Chem 276:42938-42944.

Kampinga HH, Kanon B, Salomons FA, Kabakov AE, Patterson C (2003) Overexpression of the cochaperone CHIP enhances Hsp70-dependent folding activity in mammalian cells. Mol Cell Biol 23:4948-4958.

Kazantsev A, Preisinger E, Dranovsky A, Goldgaber D, Housman D (1999) Insoluble detergent-resistant aggregates form between pathological and nonpathological lengths of polyglutamine in mammalian cells. Proc Natl Acad Sci USA 96:11404-11409.

Kazemi-Esfarjani P, Benzer S (2000) Genetic suppression of polyglutamine toxicity in Drosophila. Science 287:1837-1840.

Matsumoto M, Yada M, Hatakeyama S, Ishimoto H, Tanimura T, Tsuji S, Kakizuka A, Kitagawa M, Nakayama KI (2004) Molecular clearance of ataxin-3 is regulated by a mammalian E4. EMBO J 23:659-669.

Meacham GC, Patterson C, Zhang W, Younger JM, Cyr DM (2001) The Hsc70 co-chaperone CHIP targets immature CFTR for proteasomal degradation. Nat Cell Biol 3:100-105.

Meberg PJ, Miller MW (2003) Culturing hippocampal and cortical neurons. Methods Cell Biol 71:111-127.

Meng A, Tang H, Ong BA, Farrell MJ, Lin S (1997) Promoter analysis in living zebrafish embryos identifies a cis-acting motif required for neuronal expression of GATA-2. Proc Natl Acad Sci USA 94:6267-6272.

Nasevicius A, Ekker SC (2000) Effective targeted gene "knockdown" in zebrafish. Nat Genet 26:216-220.

Nollen EA, Garcia SM, van Haaften G, Kim S, Chavez A, Morimoto RI, Plasterk RH (2004) Genome-wide RNA interference screen identifies previously undescribed regulators of polyglutamine aggregation. Proc Natl Acad Sci USA 101:6403-6408.

Onodera O, Burke JR, Miller SE, Hester S, Tsuji S, Roses AD, Strittmatter WJ
(1997) Oligomerization of expanded-polyglutamine domain fluorescent fusion proteins in cultured mammalian cells. Biochem Biophys Res Commun 238:599-605.

Petrucelli L, Dickson D, Kehoe K, Taylor J, Snyder H, Grover A, De Lucia M, McGowan E, Lewis J, Prihar G, Kim J, Dillmann WH, Browne SE, Hall A, Voellmy R, Tsuboi Y, Dawson TM, Wolozin B, Hardy J, Hutton M (2004) CHIP and Hsp70 regulate tau ubiquitination, degradation and aggregation. Hum Mol Genet 13:703-714.

Pittman RN, Wang S, DiBenedetto AJ, Mills JC (1993) A system for characterizing cellular and molecular events in programmed neuronal cell death. J Neurosci 13:3669-3680.

Rubinstein AL (2003) Zebrafish: from disease modeling to drug discovery. Curr Opin Drug Discov Dev 6:218-223.

Sanchez I, Mahlke C, Yuan J (2003) Pivotal role of oligomerization in expanded polyglutamine neurodegenerative disorders. Nature 421:373-379.

Satyal SH, Schmidt E, Kitagawa K, Sondheimer N, Lindquist S, Kramer JM, Morimoto RI (2000) Polyglutamine aggregates alter protein folding homeostasis in Caenorhabditis elegans. Proc Natl Acad Sci USA 97:5750-5755.

Schilling G, Becher MW, Sharp AH, Jinnah HA, Duan K, Kotzuk JA, Slunt HH, Ratovitski T, Cooper JK, Jenkins NA, Copeland NG, Price DL, Ross CA, Borchelt DR (1999) Intranuclear inclusions and neuritic aggregates in transgenic mice expressing a mutant $\mathrm{N}$-terminal fragment of huntingtin. Hum Mol Genet 8:397-407.

Shimura H, Schwartz D, Gygi SP, Kosik KS (2004) CHIP-Hsc70 complex ubiquitinates phosphorylated tau and enhances cell survival. J Biol Chem 279:4869-4876.

Sittler A, Lurz R, Lueder G, Priller J, Lehrach H, Hayer-Hartl MK, Hartl FU, Wanker EE (2001) Geldanamycin activates a heat shock response and inhibits huntingtin aggregation in a cell culture model of Huntington's disease. Hum Mol Genet 10:1307-1315.

Strausberg RL, Feingold EA, Grouse LH, Derge JG, Klausner RD, Collins FS, Wagner L, Shenmen CM, Schuler GD, Altschul SF, Zeeberg B, Buetow KH, Schaefer CF, Bhat NK, Hopkins RF, Jordan H, Moore T, Max SI, Wang J, Hsieh F, et al. (2002) Generation and initial analysis of more than 15,000 full-length human and mouse cDNA sequences. Proc Natl Acad Sci USA 99:16899-16903.

Taylor JP, Hardy J, Fischbeck KH (2002) Toxic proteins in neurodegenerative disease. Science 296:1991-1995.

Trottier Y, Lutz Y, Stevanin G, Imbert G, Devys D, Cancel G, Saudou F, Weber C, David G, Tora L, Agid Y, Brice A, Mandel JL (1995) Polyglutamine expansion as a pathological epitope in Huntington's disease and four dominant cerebellar ataxias. Nature 378:403-406.

van Dellen A, Blakemore C, Deacon R, York D, Hannan AJ (2000) Delaying the onset of Huntington's in mice. Nature 404:721-722.

Venkatraman P, Wetzel R, Tanaka M, Nukina N, Goldberg AL (2004) Eukaryotic proteasomes cannot digest polyglutamine sequences and release them during degradation of polyglutamine-containing proteins. Mol Cell 14:95-104.

Wang G, Huang H, Dai R, Lee KY, Lin S, Mivechi NF (2001) Suppression of heat shock transcription factor HSF1 in zebrafish causes heat-induced apoptosis. Genesis 30:195-197.

Warrick JM, Chan HY, Gray-Board GL, Chai Y, Paulson HL, Bonini NM (1999) Suppression of polyglutamine-mediated neurodegeneration in Drosophila by the molecular chaperone HSP70. Nat Genet 23:425-428.

Willingham S, Outeiro TF, DeVit MJ, Lindquist SL, Muchowski PJ (2003) Yeast genes that enhance the toxicity of a mutant huntingtin fragment or alpha-synuclein. Science 302:1769-1772.

Wyttenbach A, Sauvageot O, Carmichael J, Diaz-Latoud C, Arrigo AP, Rubinsztein DC (2002) Heat shock protein 27 prevents cellular polyglutamine toxicity and suppresses the increase of reactive oxygen species caused by huntingtin. Hum Mol Genet 11:1137-1151.

Zoghbi HY, Orr HT (2000) Glutamine repeats and neurodegeneration. Annu Rev Neurosci 23:217-247. 